\title{
A METAFICÇÃO NA POÉTICA DE ROSA E PESSOA E O ARTIFÍCIO DAS MÁSCARAS ANAGRAMÁTICAS E HETERONÍMICAS
}

\section{METAFICTION POETIC ROSE AND THE PERSON OF MASKS AND FIREWORKS ANAGRAMMATIC AND HETERONOMY}

\section{Francisca Marta Magalhães de Brito* Instituto Federal de Educação, Ciência e Tecnologia do Piaú́}

RESUMO: A ficção literária cria um campo de encenação, onde todos os elementos se condicionam ao jogo do como se. As representações do real são transpostas para um plano de fingimento e a realidade do mundo vivencial é desmanchada, pelo que se omite e pelo se explicita, no texto literário. Do ponto de vista da teoria ficcional, as máscaras não conseguem realizar o ocultamento pleno. Como tais, devem indicar o fingimento. O estudo comparativo dos dois ícones da literatura intercontinental se baseia na teoria do efeito estético de Wolfgang Iser, com ênfase nos atos de fingir e em seus efeitos no receptor, para além da simples projeção ou da identificação com a realidade.

PALAVRAS-CHAVES: Metaficção. Fingimento. Ficcional.

\footnotetext{
Mestre em Educação pelo Instituto Pedagógico Latinoamericano Y Caribeno (2000), título revalidado pela Universidade Federal do Piauí- UFPI (2007), onde se graduou em Letras, com habilitação em Língua Portuguesa e Literaturas. Atua profissionalmente nas áreas da Educação e da Linguagem. É professora efetiva do Instituto Federal de Educação, Ciência e Tecnologia do Piauí- IFPI. Doutorado em Letras pela Universidade Federal do Pernambuco- UFPE. Recife, Pernambuco, Brasil. E-mail: martamagh@gmail.com.
} 


\begin{abstract}
Literary fiction field creates a scenario where all the elements that affect the game as. The representations of reality are translated into a plan of pretense and the reality of the experiential world is cut, so it is omitted and the explicit, the literary text. From the point of view of fictional theory, the masks can not perform the full concealment. As such, they should indicate the pretense. The comparative study of two intercontinental icons of literature based on the theory of the aesthetic effect of Wolfgang Iser, with emphasis on acts of pretense and their effects on the receiver, in addition to simple projection or identification with reality.

KEYWORDS: Metafiction. Pretending. Fictional.
\end{abstract}




\section{A METAFICÇÃO NA POÉTICA DE ROSA E PESSOA E O ARTIFÍCIO DAS MÁSCARAS ANAGRAMÁTICAS E HETERONÍMICAS}

\section{INTRODUÇÃO}

No contexto do século XX, efetuam-se mudanças paradigmáticas relacionadas ao texto literário e a sua recepção: o leitor passa a ser também um de seus construtores. A ficcionalidade e a tradicional dicotomia entre realidade e ficção são questionadas e a linguagem assume novas perspectivas, em razão dos preceitos da Linguística estruturalista, que dissemina a ideia de que a língua não representa o real, mas comunica determinada visão de mundo. $\mathrm{O}$ indivíduo percebe o mundo pelo filtro da língua. A palavra não mais representa o real, mas o cria. "A nova linguagem adquire a opacidade dos corpos que têm realidade própria." (COELHO, 1975, p. 204).

Guimarães Rosa ganha notoriedade pela busca da origem da linguagem, da transformação humana, além da literária, embora, rejeite a insígnia: “[...] quero voltar cada dia à origem da língua, lá onde a palavra ainda está nas entranhas da alma, para poder lhe dar luz segundo a minha imagem." (ROSA apud LORENZ, 1973, p. 41).

Inova na literatura, por conseguir narrar aspectos da experiência humana, de forma poética, com a participação ativa do leitor. Acerca disso, Com- 
pagnon (2001, p. 149) afirma: "o leitor é o lugar onde a unidade do texto se produz." A linguagem do escritor é uma demonstração da arte mimética, segundo Alexandre de Amorim Oliveira (2009) ', que a analisa, na obra de Rosa, diferente da noção de similitude à realidade vivida, mas como possibilidade de produção do novo: invenção. Obra e autor complexos, conforme declaração do próprio Rosa: "Note-se e medite-se. Para mim mesmo, sou Anônimo; o mais fundo de meus pensamentos não entende minhas palavras; só sabemos de nós mesmos com muita confusão. (ROSA apud RAMOS, 2009, p. 55).

Inserido em um contexto que antecede o de Rosa, Pessoa instaurou em sua arte o enigma, pela criação de "poetas personagens". A gênese dos heterônimos é revelada em conhecida carta a Adolfo Casais Monteiro, como o ponto onde se encontra sua "tendência orgânica para a despersonalização e para a simulação” (PESSOA, 1986, p. 87). Nas palavras do poeta (PESSOA, 1960), tem-se: “[...] construí dentro de mim várias personagens distintas entre si e de mim, personagens essas a que atribuí poemas vários que não são como eu, nos meus sentimentos e ideias [...]"

\section{A TEORIA DO EFEITO ESTÉTICO DE WOLFGANG ISER}

As emergentes teorias da estética da recepção atribuem papel relevante ao leitor, convocando-o à participação ativa, no processo de criação da obra de arte. Wolfgang Iser analisa a presença, nos textos de ficção, de "uma relação triádica entre o real, o fictício e o imaginário" (ISER apud LIMA, 2006, p. 282) que se opõe à dicotomia: realidade-ficção. O teórico citado concebe o fingir, a partir da repetição do real, pelo qual surgem elementos que não pertencem à realidade repetida ${ }^{2}$ :

1 OLIVEIRA, Alexandre de Amorim. Armadilhas de Sedução em Meu tio Itauaretê. Doutorando em Literatura Comparada, UERJ, publicado em fevereiro de 2009. Disponível em: http:// www.educacaopublica.rj.gov.br/biblioteca/literatura/0084.html. Acesso em: 25 abr. 2011.

2 Iser apud Lima (2006, p.282) concebe o fingir, a partir da repetição do real, pelo qual surgem elementos que não pertencem à realidade repetida: "Se o fingir não é deduzível da realidade repetida, então por ele se impõe um imaginário, que se relaciona com a realidade que volta com o texto. Ganha assim o ato de fingir sua marca própria, consistente em pro- 
Na configuração do imaginário, na sua representação textual, há perda do difuso. A realidade posta no texto é modificada pela transgressão de limites, perdendo em determinação, em precisão. A atualização do texto se dá mediante intervenção realizada leitor, através da interpretação. Ao recolher e recombinar imagens distanciadas do real, o artista torna manifesta a visibilidade do mundo, pela irrupção do poético (ISER, 1983): “o texto ficcional contém muitos fragmentos identificáveis da realidade, que, através da seleção são retirados, tanto do contexto sócio-cultural, quanto da literatura prévia ao texto."

O fictício no texto ativa o imaginário, sendo este a instância que, ao tornar a realidade um signo, transgride os limites dessa realidade, pela sua transfiguração. Isso ocorre, porque o fingir tem como objetivo: repetir a realidade de forma que ela se irrealize, como realidade vivencial e sobreviva como outra coisa. Neste ponto consiste a transgressão que o imaginário produz na realidade conhecida.

A seleção de elementos do real - primeiro ato de fingir, "recorta" o real. Este, assim configurado, e em contato com o imaginário do leitor, ativado pelo ficcional do texto, propiciará o surgimento de múltiplas combinações - segundo ato de fingir. A realidade do texto não é o real, mas é vista pelo leitor como se fosse e nisso consiste o "autodesnudamento da ficção," que corresponde ao terceiro ato de fingir.

\section{GUIMARÃES ROSA E OS POETAS ANAGRAMÁTICOS}

Candido (1964, p. 64) afirma que o traço fundamental de Guimarães Rosa é a absoluta confiança na liberdade de inventar: "é deslumbrante essa navegação nesse mar alto, esse jorro de imaginação criadora na linguagem, na composição, no enredo, na psicologia”. Isso se dá, por que: [...] "para o artista, o mundo e o homem são abismos de virtualidades” [...] (1964, p. 64).

A noção de virtualidades do mundo e do homem encontra aporte em Rosa, que comenta a multiplicidade de pessoas em si, na obra Tutaméia

vocar a repetição, no texto, da realidade vivida, (lebensweltiche Realitàti), por esta repetição conquistando o imaginário uma configuração, pela qual a realidade repetida se transforma em signo e o imaginário em efeito (Vorstell-barkeit) do assim designado". 
(Terceiras Estórias): "E precisaria cada um, para simultaneidades no sentir e no pensar, de vários cérebros e corações. Quem sabe, temos?" ${ }^{3}$ É reconhecido pela sua inventividade e capacidade de fabulação. Sobre o processo se sua criação e seus efeitos, o autor refere: "tento evitar os recifes da incessante tempestade de minha vida interior", e, ainda: "um tormento acaparador, de ambicioso, de insaciável”. (ROSA apud GALVÃO, 2008, p. 171).

A turbulência psíquica que dele se apossava ao criar é revelada em uma carta: "Eu ando febril, repleto, com três livros prontos na cabeça, um enxame de personagens a pedirem pouso em papel. [...]. É coisa dura, e já me assusto, antes de pôr o pé no caminho penoso, que já conheço." (GALVÃO, 2008). Declara que o trabalho é árduo e lhe causa dor, mas que a recusa em fazê-lo também lhe trará dor. O livro, se não for escrito, "fica coagulado na gente, como um trombo na veia, pior que um complexo." (GALVÃO, 2008). Entre as duas dores, Rosa opta pela de escrever e a sua arte se configura como prosa poética.

Os indícios da existência de poetas em Guimarães Rosa surgem em um volume que reúne estudos, escritos inéditos, discursos, pareceres e outros textos, acrescidos de uma bibliografia organizada por Plínio Doyle (1968), intitulado Em Memória de João Guimarães Rosa, Editora José Olympio. Segundo Doyle, a primeira pista foi encontrada na publicação da Antologia de poetas brasileiros bissextos contemporâneos (2 ed. s/d, Org. Simões), de Manuel Bandeira, na qual foram publicados seis poemas do escritor, assinados pelo anagramático Soares Guiamar.

Doyle, em pesquisa no jornal O Globo, onde os poemas haviam sido publicados, descobre mais doze poemas e dois pseudônimos: Meuriss Aragão e Sá Araújo Ségrim. O primeiro anagramáticos de Guimarães Rosa e o último, de João Guimarães Rosa. Segundo Doyle, boa parte dos escritos de Rosa, em O Globo, no ano de 1961, destinou-se aos livros: Primeiras Estórias (de 1962), Tutaméia (de 1967) e Ave Palavra (de 1970). Duas das obras, em fase de preparo, só foram publicadas postumamente: Estas estórias (de 1969) e Ave, palavra (de 1970), um livro de contos e uma coletânea de tex-

${ }^{3}$ Walnice Nogueira Galvão em ensaio intitulado "Heteronímia em Guimarães Rosa" (In: Mínima mímica, 2008, p. 167-168), analisa os poetas anagramáticos de Rosa e realiza uma espécie de "arrolamento" destes, a partir dos introitos existentes nos blocos de poemas de Ave Palavra. 
tos variados. Os anagramáticos estão nos introitos dos grupos de poemas, em Ave palavra. Romaguari Sães só aparece no livro, juntando-se ali aos já existentes. Walnice analisa que as personalidades poéticas em Rosa não têm a complexidade dos heterônimos de Pessoa.

Rosa propõe a criação de novos sistemas de pensamento e de linguagem, pela inversão, pelo riso e por meio da criação de novas palavras, a partir de suas matrizes arcaicas, miscigenando-as aos termos regionais, elaborando uma língua capaz de mover-se, em uma dança que se aproxima do cultural, do sertão-mundo, de onde visualiza o seu próprio universo e a si. Apresenta suas máscaras anagramáticas, em um primeiro conjunto: "SÁ ARAÚJO SÉGRIM - poeta comprido - é outro dos anagramáticos, de que hoje disponho. Se bem talvez um tanto discípulo de SOARES GUIAMAR, sob leves aspectos, sofre só e sozinho verseja. Sei que pensa em breve publicar livro: o "Segredeiro", e do supracitado é, às vezes, o que prefiro. Será que conosco concordam?" (ROSA, 1970, p. 105) No segundo conjunto, esboça uma explicação para a reaparição do anagramático:

"SE NÃO LHE FIRO A MODÉSTIA, direi, aqui, depressa, que SÁ ARAÚJO SÉGRIM, em geral, agradou. Por isso mesmo, volta, hoje, com novos poemas, que só não sei se escolhemos bem. Sendo coisas mui sentidas." (ROSA, 1970)

\section{FERNANDO PESSOA E SEUS HETERÔNIMOS}

Pessoa assume o distanciamento, possibilitado pela criação de heterônimos, conforme assinala Bernardo Soares, no Livro do Desassossego:

Criei em mim várias personalidades. Crio personalidades constantemente. Cada sonho meu é imediatamente, logo ao aparecer sonhado, encarnado numa outra pessoa, que passa a sonhá-lo, e eu não.

(PESSOA, 2011) 
A multiplicidade contribui para o desenvolvimento do projeto estético desse poeta, na medida em que o "distancia" de uma sociedade alheia ao seu processo construtivo. Compôs em seu próprio nome, criou Alberto Caeiro, Ricardo Reis, Álvaro de Campos, dentre outros de menor complexidade - questão que se traduz na distinção pseudônimo/heterônimo, detalhada pelo próprio poeta: "A obra pseudônima é do autor em sua pessoa, salvo no nome que assina; a heterônima é do autor fora de sua pessoa; é duma individualidade completa fabricada por ele, [...] (PESSOA apud HARANAKA, 1981)."

Ser plural foi proclamado condição essencial à poética moderna, por Álvaro de Campos, no manifesto Ultimatum": "Só tem o direito ou o dever de exprimir o que sente, em arte, o indivíduo que sente por vários”. A necessidade da multiplicação do Eu para o englobamento de todos os estímulos é enfatizada, pelo heterônimo: "Os estímulos da sensibilidade aumentam em progressão geométrica; a própria sensibilidade apenas em progressão aritmética" (TELLES, 1982, p. 248).

Fernando Pessoa, nascido em 1888, é contemporâneo da idade mecânica, que, segundo Marshall McLuhan (1995), fragmenta o Homem. A sensibilidade na "idade mecânica" é estilhaçada, provocando no indivíduo o "poder de agir sem reação”, o não-envolvimento. Em reação a essa fragmentação, Pessoa assume uma postura genial: multiplica-se para conquistar o envolvi-

4 Em sua dissertação de Mestrado, Paulo Jorge Haranaka cita declaração de Fernando Pessoa na revista Presença, em texto que realiza a distinção entre a criação pseudônima da criação heterônima. (PESSOA apud HARANAKA, 1981, p.04).

5 Manifesto Futurista, na voz do heterônimo Álvaro de Campus, 1917.

6 A “era mecânica”, segundo McLuhan (1995), é fruto da tecnologia produzida pelo alfabeto fonético, que "produz uma divisão tão clara da experiência, dando-nos um olho por um ouvido e liberando o homem pré-letrado do transe tribal, da ressonância da palavra mágica e da teia do parentesco" (1995, p. 103). Essa "liberdade" produzida pelo alfabeto fonético acabou por fragmentar o homem ocidental, fazendo com que ele sofresse a "compartimentação de sua vida sensória, emocional e imaginativa" (1995, p. 107), o que possibilitou a ele se distanciar do mundo e alcançar a capacidade analítica e generalizadora de organizar a vida. Citando novamente McLuhan: "Se o homem ocidental sofre a dissociação de sua sensibilidade interna pelo emprego do alfabeto, também conquista a liberdade pessoal de dissociar-se do clã e da família" (1995, p. 107). Com a chegada da "era Gutenberg", essa fragmentação foi acelerada até chegarmos aos nossos dias com a "era fordiana" de divisão e especialização do trabalho, a qual, por seu turno, vai abrindo caminho para uma nova fase de envolvimento total - a "era eletrônica". 
mento com o todo. Novamente, em Ultimatum (1917), a voz artística alude à busca do envolvimento total: "Devemos, pois operar a alma, de modo a abri-la à consciência da sua interpretação com as almas alheias, obtendo assim uma aproximação do Homem-Completo, Homem-Síntese da Humanidade."

Pessoa cria textos que dialogam entre si no imaginário dos leitores, produzindo de maneira engenhosa a "progressão geométrica" da nossa sensibilidade. O poeta a que McLuhan ${ }^{7}$ chamou de "homem da consciência integral, aquele que "em qualquer campo, científico ou humanístico, percebe as implicações de suas ações e do novo conhecimento de seu tempo". Ao criar vozes poéticas plurais, através dos seus heterônimos e do ortônimo, situando-os historicamente, e demarcando os estilos próprios de cada personalidade, realizou em profundidade a multiplicidade, apontada pelos movimentos vanguardistas como produto de uma nova civilização.

\section{A METAFICÇÃO NA POÉTICA DE ROSA E PESSOA}

A capacidade de criar mundos imaginários, para além da realidade objetiva, é tão enigmática, quanto o limite da genialidade artística. Bernardo, (2010, p.12) analisa que: "Um dos mecanismos privilegiados da formulação ficcional de enigmas reside no fenômeno estético da metafição que por definição se dobra e redobra de fora para dentro." Segundo Bernardo (2010), a metaficção sempre existiu na ficção, mas o termo metaficção é de uso recente: "William Gass o cunhou como "metaficcion", designativo dos novos romances americanos do século XX", que subvertem os elementos narrativos canônicos, pelo desenvolvimento de um jogo intelectual, estabelecido com a memória literária: um diálogo entre ficções. O teórico define metaficção (2010) como sendo: "uma ficção fundada na elaboração de ficções".

Na recepção de um texto literário, o leitor se apropria da máscara do "outro ficcional" para experimentar em si o que antes não ousava. $\mathrm{O}$ efeito estético é determinado pelo distanciamento crítico interior, em que o sujeito supera sua própria indeterminação, no reencontro de seu potencial mais

MCLUHAN, Marshall. Os Meios de Comunicação Como Extensões do Homem. São Paulo, Cultrix, 10 ed., 1995. 
criativo. A identificação com a máscara do outro, oferecida pelo texto ficcional, oportuniza ao leitor observar-se de fora de si. Tal experiência inaugura a distância que produz o autoconhecimento. $\mathrm{O}$ efeito estético se desvincula da projeção subjetiva, aliando-se à vivência do conhecimento. Logo, a narrativa literária retira o sujeito de duas alienações: a narcísica e a sócio-cultural.

Segundo Pessoa (1960), quando a multiplicidade se instaurar, de modo orgânico, no fazer poético, o poeta terá chegado ao seu máximo, no processo de criação: "e teremos um poeta que seja vários poetas, um poeta dramático escrevendo em poesia lírica." Na mencionada carta a Adolfo Casais Monteiro, o poeta deixa entrever a existência de uma possível organicidade na criação dos heterônimos: "É sério tudo o que escrevi sob os nomes de Caeiro, Reis, Álvaro de Campos. Em qualquer destes pus um profundo conceito de vida, diverso em todos três, mas em todos gravemente atento à importância misteriosa de existir."

Se os diversos "Pessoas" são distintos, por outro lado, são contemporâneos, situados nas correntes europeias da época e sofrendo semelhantes crises de valores e de consciência. A heteronímia em Pessoa revela uma intensa navegação íntima, em busca do conhecimento, para além das suas diversas inclinações, ou seja, para além das "Máscaras" ou das "Personas".

A invenção de nomes é um dos aspectos significativos em sua obra e não se restringe à invenção de neologismos. $\mathrm{O}$ artista estendeu a sua construção linguística à criação de poetas anagramáticos, de Guimarães Rosa: Soares Guiamar, Meuriss Aragão, Romaguari Sães; e de João Guimarães Rosa: Sá Araújo Ségrim

Identificam-se outras "presenças" poéticas recorrentes na prosa do escritor, disfarçadas em canção folclórica, notas, citações. Galvão (2008), refere-se a um "despistamento visível", afirmando que as "citações" não fornecem elementos suficientes à pesquisa, concebendo-as como "malabarismos do escritor". Para a pesquisadora, João Barandão é “[...] o mais ubíquo dos poetas do prosador." Descreve a sua aparição em "Cara-de-Bronze" e Corpo de baile, através de citações "das Cantigas de serão, de João Barandão". O trovador e as mesmas cantigas são mencionados, em Tutaméia (Terceiras Estórias)com três versos em "Barra da vaca"; e outra no corpo do texto de "Melim Meloso” e em Estas estórias, “Com o vaqueiro Mariano.” (GALVÃO, 2008). 


\section{CONCLUSÃO}

Enquanto estratégia metaficcional, os poetas anagramáticos na obra de Rosa, permitem-lhe apresentar suas impressões a sua criação. O discurso em terceira pessoa, propiciador do distanciamento, concede-lhe também a primeira crítica. Através das máscaras anagramáticas, Rosa se distancia e se aproxima da sua composição artística, na dança da metapoese. Os anagramáticos possuem as marcas do nome de seu criador, em combinações diversas e estilo coerente. $\mathrm{O}$ ocultamento não se realiza em plenitude, pois, na condição de máscaras, indicam o disfarce: “[...] os introitos fornecem sucintas notas biográficas que entretêm entre si um elegante jogo de máscaras" (GALVÃO, 2008).

A multiplicidade em Fernando Pessoa contribui para a realização do seu projeto estético, pelo distanciamento. Pessoa instiga os leitores de sua poesia enigmática e metaficcional, ancorada no trabalho com a linguagem e no fenômeno ímpar da heteronímia. Poeta de grande pluralidade e densidade psicológica, "subdividiu-se" ou "multiplicou-se", criando máscaras heteronímicas? A resposta talvez se encontre em fragmento enunciado de Ultimatum (1917), na voz do heterônimo futurista: “[...] operar a alma, de modo a abri-la à consciência da sua interpretação com as almas alheias, obtendo assim uma aproximação do Homem-Completo, Homem-síntese da Humanidade."

\section{REFERÊNCIAS}

BERNARDO, Gustavo. O Livro da metaficção. Rio de Janeiro: Tinta Negra Bazar Editorial, 2010.

CANDIDO, A.; CASTELO, J. A. Presença da literatura brasileira: Modernismo. São Paulo: DIFEL, 1983.

CANDIDO, A. O homem dos avessos. In: . Tese e antítese. São Paulo: Nacional, 1964. p. 121-140 
COMPAGNON, Antoine. O demônio da teoria: literatura e senso comum. Tradução: Cleonice Paes Barreto Mourão, Consuelo Fortes Santiago. Belo Horizonte: Ed. UFMG, 2001.

COELHO, N. N. Guimarães Rosa e a tendência regionalista. In: ÁVILA, A. (Org.). O Modernismo. São Paulo: Perspectiva, 1975. p. 203-211.

DOYLE, Plinio. Bibliografia de \& sobre Guimarães Rosa. In: Em memória de João Guimarães Rosa. Rio de Janeiro: José Olympio, 1968. p. 193-225.

GALVÃO, Walnice Nogueira. Mínima mímica: ensaios sobre Guimarães Rosa. São Paulo: Companhia das Letras, 2008.

HARANAKA, Paulo J. Leituras de João Guimarães Rosa, poeta. 1981. Dissertação (Mestrado) - Universidade de São Paulo, Faculdade de Filosofia, Letras e Ciências Humanas, 1981.

ISER, Wofgang. Os atos de fingir ou o que é fictício no texto ficcional. In: COSTA LIMA, L. (Org). Teoria da literatura em suas fontes. vol. II. Rio de Janeiro: Francisco Alves, 1983. p. 384-416.

LIMA, Luiz Costa. História. Ficção. Literatura. São Paulo: Companhia das Letras, 2006.

LORENZ, G. W. Guimarães Rosa. In: Diálogo com a América Latina: panorama de uma literatura do futuro. Trad. R. C. Abílio e F.S. Rodrigues. São Paulo: E.P.V., 1973.

MCLUHAN, Marshall. Os Meios de Comunicação Como Extensões do Homem. 10 ed. São Paulo, Cultrix, 1995.

OLIVEIRA, Alexandre de Amorim. Armadilhas de sedução em meu tio o Itauaretê. Revista Educação Pública, Rio de Janeiro, 2009. Disponível em : 
http://www.educacaopublica.rj.gov.br/biblioteca/literatura/0084.html. Acesso em: 25 abr. 2011.

PESSOA, F. Obra poética. Organização, introdução e notas de GALHOZ, Maria Aliete Dores. Rio de Janeiro: Ed José Aguilar, 1960.

F. Obra poética e em prosa. Porto: Lello \& Irmão, 1986.

F. Guimarães Rosa. In: COUTINHO A. (Org.). A literatura no Brasil. São Paulo: Global, 2001. p. 475-526.

F. Livro do Desassossego. Bernardo Soares. Disponível em: http:// www.dominiopublico.gov.br/pesquisa/DetalheObraForm.do?select_ action=\&co_obra=24204. Acesso em: 22 jun. 2011.

RAMOS, Jacqueline. Risada e Meia: Comicidade em Tutaméia. São Paulo: Annablume, 2009.

ROSA, J. G. Ave, palavra. Rio de Janeiro: José Olympio, 1970.

TELLES, Gilberto Mendonça. Vanguarda Moderna e Modernismo Brasileiro. Petrópolis (RJ): Editora Vozes, 1982. 